\title{
INCOMING AND OUTGOING CT READINGS BASED AI TECHNIQUES FOR BUS BAR DIFFERENTIAL PROTECTION FAULTS ANALYSIS
}

\author{
Mohamed Mahmoud Ismail ", M. A. Moustafa Hassan \\ Electrical Power and Machine Depart. Faculty of Engineering Helwan University
}

Received 9 March 2013, accepted 25 May 2013

\begin{abstract}
The application of artificial intelligent approaches was introduced recently in protection of distribution networks. In this paper, the application of Adaptive Neuron Fuzzy Inference System (ANFIS) as well as artificial Neural Network (ANN) for protection of bus bars will be illustrated. The objective of this paper is firstly, to detect the fault occurrence on bus bar, secondly location of the fault. The fault detection and location are firstly trained using ANN and ANFIS techniques and then they are tested in diversity of system conditions with respect to the fault types, inception instant, resistance and pre fault conditions. The fault detection and location units used current magnitude difference change at fault and Pre-fault conditions for incoming and outgoing CTs. The fault location unit in this paper is to detect if the fault occurs internally on the bus bar or externally. The protection system selection depends on the time as the system should take the correct action at fault condition, sending correct tripping signal for internal fault conditions and prevent the maloperation due to external fault conditions. On other hand, the fault clearing time is very important issue to avoid more damage to power system equipments. From the simulation, it is found that the proposed system success to detect the fault and clarify the fault location at different fault cases within a short detection time than obtained in the previous work.
\end{abstract}

Keywords : busbar prptection, AI techniques, current transformers.

\section{Introduction}

Bus bars are the most important component in a distribution network. They can be open bus bars in an outdoor switch yard, up to several hundred volts, or inside a metal clad cubicle restricted within a limited enclosure with minimum phase -to phase and phase-toground clearances. Insulated bus bars are normally in small length sections and interconnected by hardware. Their form and electrical 'node' where many circuits come together, feeding in and sending out power was given in [1]. In power system network, a bus is a connection point for many generation, transmission, or load circuits. If a fault occurs on a bus, all circuits which supplies the fault current, must trip to isolate the fault. A bus fault may result in considerable loss of service and severe system disturbance. Station arrangements are often designed to minimize the number of circuits that must be opened for a bus fault. As a result of improved continuity of energy supplies and flexibility of system operations, some power system stations use complex bus arrangements that increase demands for sophisticated bus protection schemes .Protection zone selection must be highly discriminative, such that a bus relay operates only for a protection zone fault. Protection of bus bar demands high standards. Failure to trip on an internal fault or false tripping of a bus bar during load service and external fault both have disastrous effects on the stability of power systems, and may even cause complete blackouts as given in [2]. Slow fault clearing results additionally in extensive damage at the fault location as a consequence of the generally high concentration of short circuit power at station buses. More than with other circuit protection methods intensified emphasis is therefore put on

\footnotetext{
* Corresponding author.

E-mail address: m_m_ismail@yahoo.com
} 
Mohamed Mahmoud Ismail, M. A. Moustafa Hassan, Incoming and outgoing CT readings based AI techniques for bus bar differential protection faults analysis, pp. 1595-1611

the essential requirements of speed and stability [3] .A further important point to consider is through - fault stability with current transformer saturation as illustrated in [4-7]. The successful protection can be achieved subject to compliance with the following as presented in $[8,9]$ :

a) Selectivity, trip only the faulted equipment.

b) Stability, not to operate for faults outside the zone, most important for bus bars and stability must be guaranteed. Reasons for loss of stability are the interruption of Current Transformer (CT) or the accidental operation during testing.

c) Tripping can be arranged by two-out-of-two, zone and check relays.

d) Speed, limit damage at fault point.

A bus bar is a power system element that does not extend over long distances (as transmission lines do) and it is ideally protected by a differential relay. Considering a bus bar and its associated circuits consisting of lines and transformers. The algebraic sum of all the circuit currents must be zero when there is no bus fault. For all circuit, CT ratios being equal and the secondary currents also add to zero when there is no bus fault. The various CT inaccuracies require that a percentage differential relay be used, but in this case the percentage slope can be quite small, as there are no mismatched ratios or tap changers to be concerned. Also there is no magnetizing inrush phenomenon to be considered. One area of concern is the saturation of a CT during an external fault. In general the core of a properly chosen CT should not saturate with in $1 / 2$ to 1 cycle of fault inception as illustrated in [3]. However, often the requirement placed on bus differential relays is that they should restrain from operating for external faults even if a CT should saturate in $1 / 4$ cycle or less after the occurrence of a fault. This requirement places a very confining restriction on a computer based bus bar differential relay as explained in [10]. Differential protection schemes are applied for high voltage bus bars. Failure - to- trip on an internal fault, as well as false tripping of a bus bar during a load service or in case of external fault, both have disastrous effect on the stability of power systems [6,7]. The challenge of bus differential protection is the issue of false differential current due to CT saturation and ratio mismatch [8]. The bus bar protection can be classified as high impedance and low impedance types. High impedance relays are used to provide low cost bus protection [9], but have limitations due to complex arrangements and use of multi ratio current transformers. The low impedance measuring principle employs the zone -selective differential current as the operating quantity and the sum of the current magnitudes as the stabilizing signal. The measuring principle must ensure protection with CT saturation on external faults [10]. A low -impedance bus bar protection operates during CT saturation by using a principle, which discriminates between saturated and un saturated wave forms. Recently, many novel differential techniques have been proposed to overcome CT saturation [4-7]. For external faults, the differential current should be zero, but errors caused by CT saturation can result in a non zero value. To prevent mal operation, the operating threshold is raised by increasing the bias setting. Raising the bias threshold has detrimental effect on the relay sensitivity as it prevents the detection of in -zone resistive faults. The impact of CT ratio bias characteristics reduces the sensitivity of the relay. A new digital relaying technique for bus bar protection using phase angle change in sequence current of incoming CT currents and outgoing CT currents is used in this article as shown in Figure.1. The angle differences of during fault and pre-fault currents signals of incoming and outgoing CT's are the indicators of external or internal faults for bus bar protection. The Phasor concepts are used to overcome the current transformer saturation. The major advantage of the proposed

Journal of Engineering Sciences, Assiut University, Faculty of Engineering, Vol. 41, No. 4, July, 2013,E-mail address: jes@aun.edu.eg 
Mohamed Mahmoud Ismail, M. A. Moustafa Hassan, Incoming and outgoing CT readings based AI techniques for bus bar differential protection faults analysis, pp. 1595 - 1611

technique is that it does not require additional voltage signal for discriminating internal and external faults. Another advantage of method is that it does not use magnitude information of the current only for discriminating the fault and thus overcomes the CT saturation issues. The positive sequence component is used as such as a component is available for both unbalanced and balanced faults .The mentioned scheme is deterministic computations assuming system modeling based on conventional mathematical tools, and they are not well suited for dealing with ill defined and uncertain systems. The method of Laplace transform of the bus bar protection is discussed in [11], while many techniques was used for bus bar protection as indicated in [12-19]. The method of Adaptive Neuro Fuzzy Inference System (ANFIS) is used for bus bar protection presented in $[12,18]$. The technique of wavelet package transform is also used for this purpose as shown in [14]. This paper is an improvement of the previous researches [12-17], the phase angle change in sequence current of incoming CT currents and outgoing CT currents only without using the voltage signals is used and it does not use magnitude information of the current only bust use also the phase angle for discriminating the fault and thus overcomes the CT saturation issues. Also this paper is an improvement of [18]. The artificial neural network (ANN) technique as well as the Adaptive Neuro Fuzzy Inference System (ANFIS) for the bus bar protection scheme are initialized.

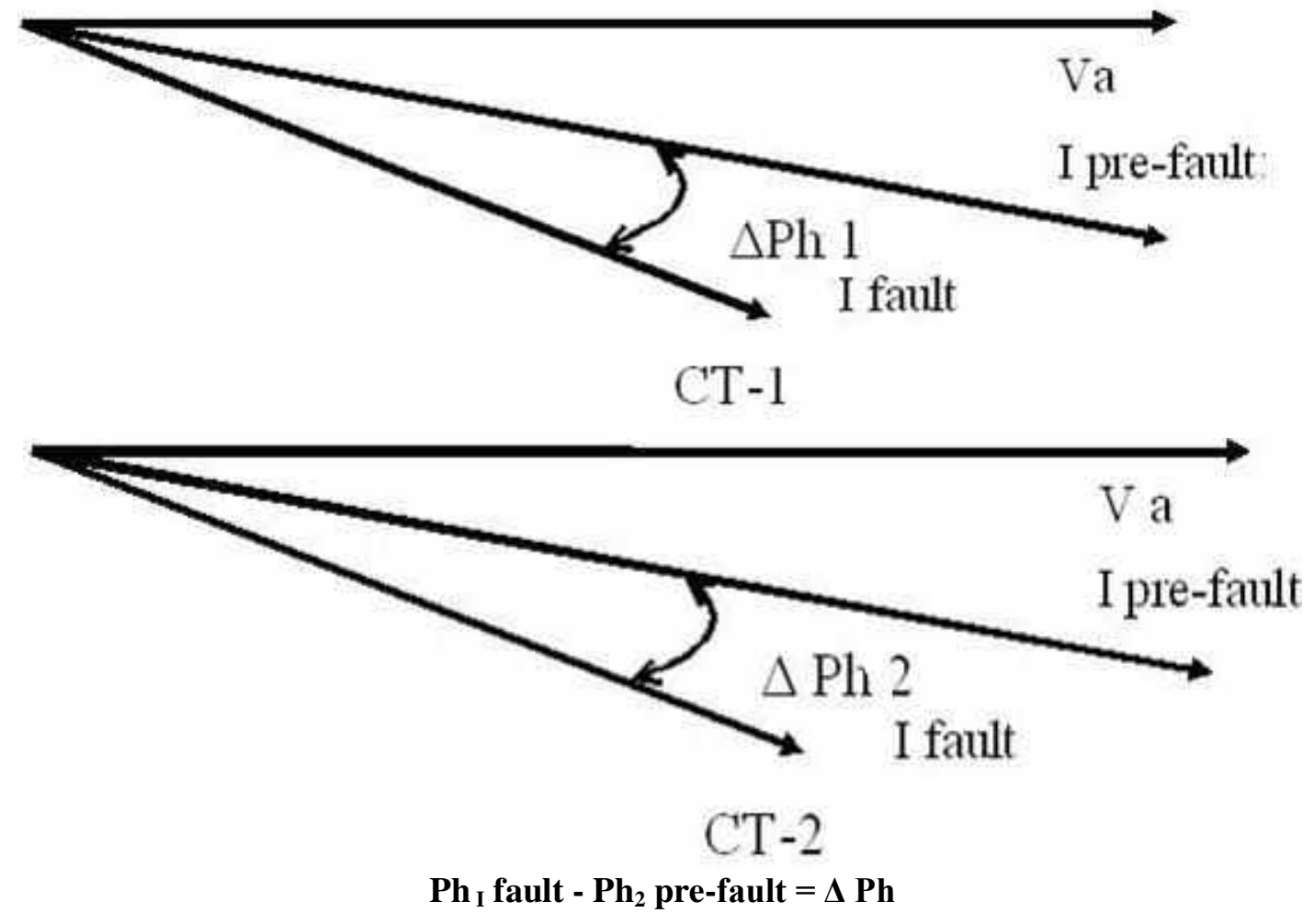

Fig. 1. Phasor Diagram

Journal of Engineering Sciences, Assiut University, Faculty of Engineering, Vol. 41, No. 4, July, 2013,E-mail address: jes@aun.edu.eg 
Mohamed Mahmoud Ismail, M. A. Moustafa Hassan, Incoming and outgoing CT readings based AI techniques for bus bar differential protection faults analysis, pp. 1595-1611

\section{The intelligent techniques types}

The power system protection approaches are based on deterministic computations on a well defined model of the system to be protected. This results in taking system variation into account as the rules are fixed. They do not have the ability to adapt dynamically to the system operating conditions and to make correct decisions if signals are uncertain. Recently, intelligent soft computational techniques of human knowledge features are required. This intelligent soft computational techniques like the following as illustrated in [19].

a) Fuzzy Inference System (FIS): Fuzzy system is a non liner - mapping between inputs and outputs. Fuzzy logic has the advantage that the solution to the problems can be cast terms that human operators can understand in form of IF- THEN rules, so that their experience can be used in the design of the controller system. This makes it easier to mechanize tasks that are already successfully performed by humans, on other hand. FIS is, depend on fixed membership functions. It can't be adjusted to compensate the error at the output of FIS controller

b) Artificial Neural Networks (ANN): ANN is defined as they are simply a class of mathematical algorithms to solve a number of specific problems. It has learning facilities to compensate the error output error by adjusting the weights.

c) Adaptive Neural Fuzzy Inference System (ANFIS):

It is observed from the study of (FIS) and (ANN) that the modeling of differential protection System by using any one of them will be very complex. The power system operation in transient period cannot be easily described by artificial explicit knowledge, because it is affected by many unknown parameters. These drawback of (FIS) and (ANN) are overcome by the integration between the (ANN) technology and the fuzzy logic system , to originate another artificial intelligence technique called .Adaptive Neuro Fuzzy Inference System (ANFIS). This paper is integrating the learning capabilities of (ANN) to the robustness of fuzzy logic systems in the sense that fuzzy logic concepts are embedded, and to provides a natural frame work for combining both numerical information in the form of input / output pairs and linguistic information in the form of IF -THEN rules in a uniform fashion as presented in [19]. In This paper the proposed differential protection relay is applied on $110 \mathrm{KV}$ bus bar using phase angle change in positive sequence current of incoming CT and outgoing CT as shown in Figure.2. The fault detectors and locators are instituted by the ANN and (ANFIS) training, and then they are tested in variety of system conditions to ensure the robustness and the comprehensive of the proposed protection scheme.

\section{Proposed method}

In this paper, we build up model of the system $13.8 \mathrm{KV}, 100 \mathrm{MVA}$ supply RL load 50 MVA at $13.8 \mathrm{KV}$ using $630 \mathrm{~mm}^{2}$ power cables between the generator and the load with length 1000 meters .

Journal of Engineering Sciences, Assiut University, Faculty of Engineering, Vol. 41, No. 4, July, 2013, E-mail address: jes@aun.edu.eg 
Mohamed Mahmoud Ismail, M. A. Moustafa Hassan, Incoming and outgoing CT readings based AI techniques for bus bar differential protection faults analysis, pp. $1595-1611$

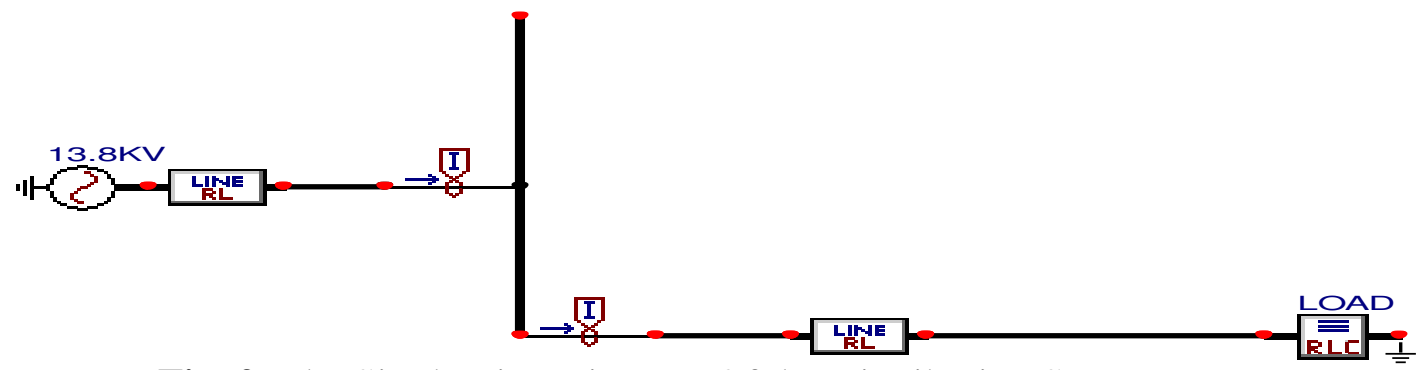

Fig. 2. The Single Line Diagram Of the Distribution System

The parameters of the distribution system will be as following:

- Generator:

$\mathrm{V}=13.8 \mathrm{KV}, \mathrm{F}=50 \mathrm{HZ}, \mathrm{S}=100 \mathrm{MVA}, \mathrm{R} \mathrm{g}=2.112 \Omega, \mathrm{X} \mathrm{g}=0.1904 \Omega, \mathrm{P} . \mathrm{F}=0.8, \Phi$ $=0.6435 \mathrm{rad}$

- Power cable:

$\mathrm{R}$ cable/ phase $=0.0283 \Omega / \mathrm{KM}, \mathrm{L}$ cable/phase $=0.299 \mathrm{mH} / \mathrm{KM}, \mathrm{X}$ cable $/ \mathrm{phase}$ $=\omega * \mathrm{~L}=0.0939 \Omega / \mathrm{KM}, \mathrm{L}$ cable $=1 \mathrm{KM}$

Load current $3,623.188 \mathrm{~A}$ and $630 \mathrm{~mm}^{2}$ cable current rate 1,103 A so we need 4 cable /phase. $\mathrm{Z}$ cable /phase will be the result of four cables in parallel.

$\mathrm{R}$ cable $/$ phase $=$ Zcable $/$ phase $* \cos \Phi=1.882384 * 10-4 \Omega$

Xcable $/$ phase $=$ Zcable $/$ phase $* \sin \Phi=1.4118 * 10-4 \Omega$

\section{- Load :}

$\mathrm{S}$ load $=50 \mathrm{MVA}, \mathrm{V}=13.8 \mathrm{KV}, \mathrm{Z}$ total $=\mathrm{Z}$ load $+\mathrm{Z}$ Cable $+\mathrm{Z} \mathrm{g}$

$\mathrm{I}=(\mathrm{S}$ load $/ \mathrm{V})=3,623.188 \mathrm{~A}, \mathrm{Z}$ total $=(\mathrm{V} / \mathrm{I})=3.81 \Omega$

$3.81=\mathrm{Z}$ load $+3.2 * 10-3+1.72$

$\mathrm{Z}$ load $=2.0868 \Omega, \mathrm{R}$ load $=2.0868 \operatorname{Cos} \Phi=1.66944 \Omega, \mathrm{X}$ load $=2.0868 \operatorname{Sin} \Phi$ $=1.252 \Omega$

$\mathrm{I} \max$ short $=(\mathrm{S}$ rate $/ \mathrm{V})=(100 * 106 / 13.8 * 103)=7,246.3768 \mathrm{~A}$

There are two current meters to measure the current entering and leaving the bus bar and they act the CT at power system ( CT1 \& CT2)

\subsection{Bus Bar modeling using ATP program}

A single line diagram of protected bus bar using ATP program is shown in Figure.3. It consist of $110 \mathrm{KV}$ bus bar Systems with two feeders incoming and outgoing. The incoming feeder is connected to $110 \mathrm{KV}, 500 \mathrm{MVA}$ source. The outgoing feeder is connected to the load. Bus bar is protected by differential protection consist of two Current Transformer (CT) with ratio 1200/5. The One on incoming feeder is called incoming CT. The other on outgoing feeder is called outgoing CT. The current transformer is represented by ATP as ideal transformer, Type 93 non linear inductor (Magnetizing branch) and series resistance ( burden resistance ) .

Journal of Engineering Sciences, Assiut University, Faculty of Engineering, Vol. 41, No. 4, July, 2013,E-mail address: jes@aun.edu.eg 
Mohamed Mahmoud Ismail, M. A. Moustafa Hassan, Incoming and outgoing CT readings based AI techniques for bus bar differential protection faults analysis, pp. 1595-1611

3.2. The differential relay model using MATLAB SIMULINK

The differential relay model using MATLAB SIMULINK is illustrated in Figure.4. It consist of fault detection unit and fault location unit .

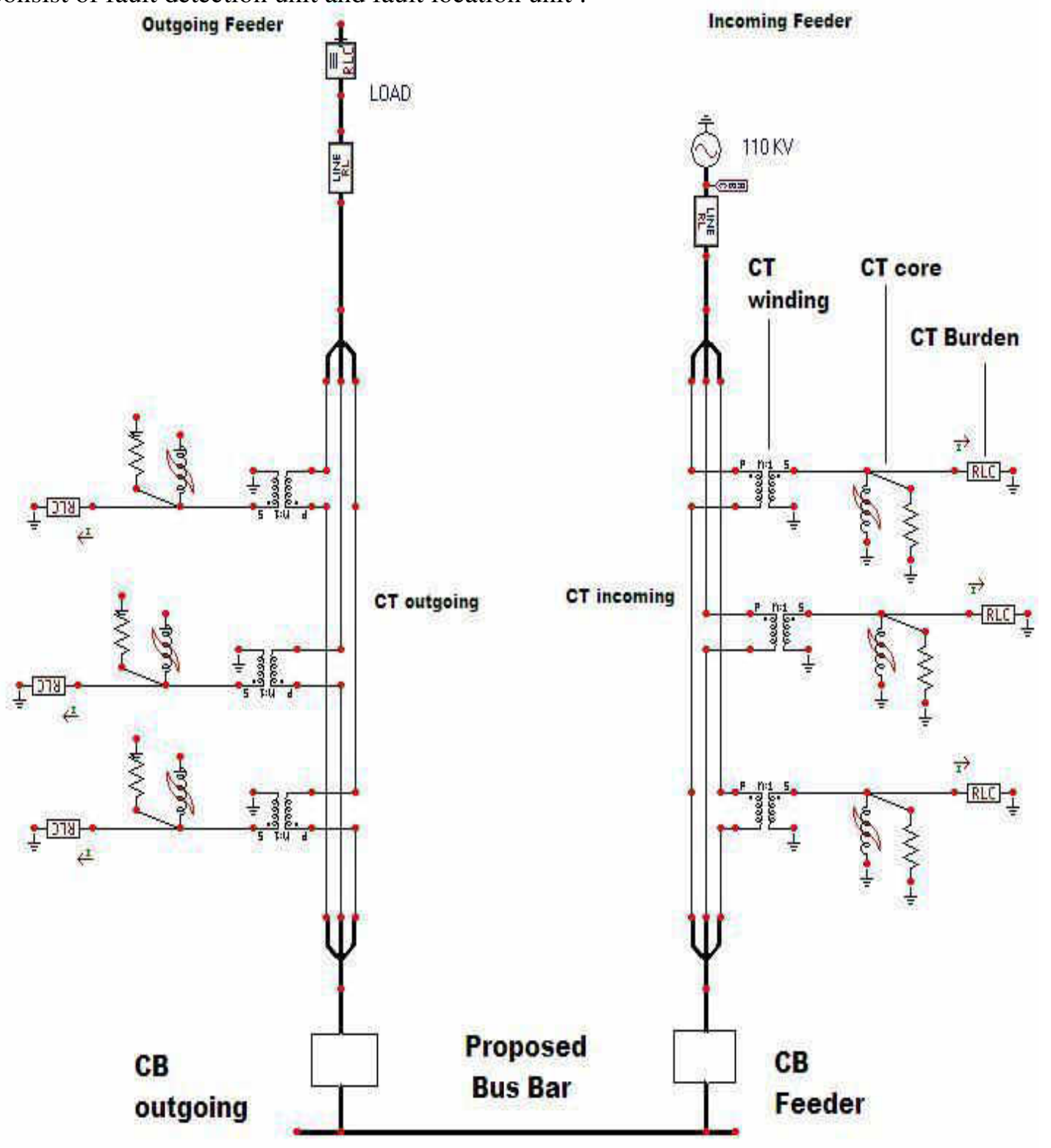

Fig.3. Bus bar Single Line Diagram using ATP Program

Journal of Engineering Sciences, Assiut University, Faculty of Engineering, Vol. 41, No. 4, July, 2013,E-mail address: jes@aun.edu.eg 
Mohamed Mahmoud Ismail, M. A. Moustafa Hassan, Incoming and outgoing CT readings based AI techniques for bus bar differential protection faults analysis, pp. $1595-1611$

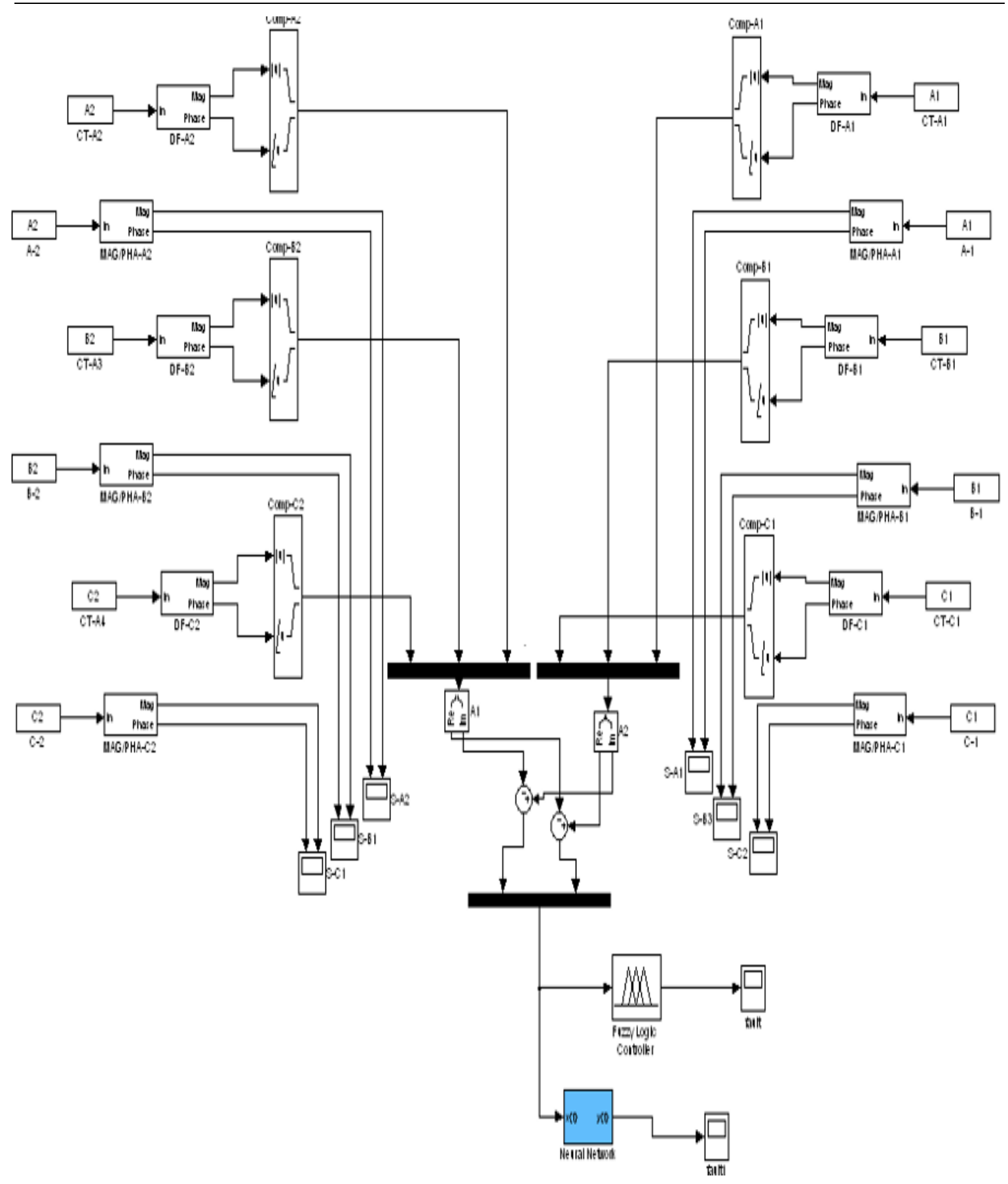

Fig. 4. Bus Bar Fault Detection using MATLAB Simulink

Journal of Engineering Sciences, Assiut University, Faculty of Engineering, Vol. 41, No. 4, July, 2013,E-mail address: jes@aun.edu.eg 
Mohamed Mahmoud Ismail, M. A. Moustafa Hassan, Incoming and outgoing CT readings based AI techniques for bus bar differential protection faults analysis, pp. 1595-1611

\section{Fault detection controller design}

The controller design will handle two types of controller detection and location, both works together as one system to take the correct decision toward the protection system operation. The fault detection chart for bus bar protection is indicated in figure 5 .

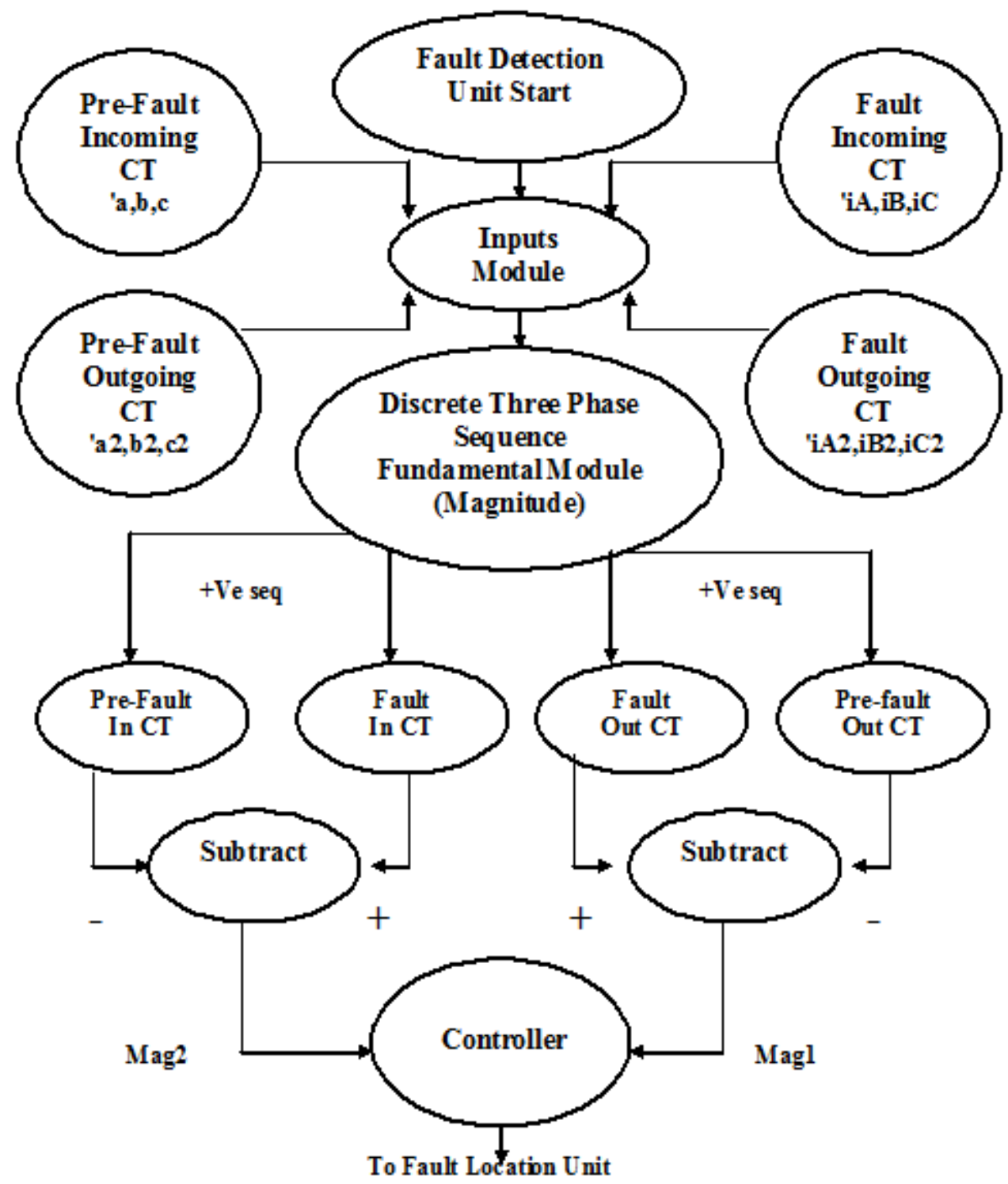

Fig. 5. Fault Detection Chart for bus bar Protection Scheme

Journal of Engineering Sciences, Assiut University, Faculty of Engineering, Vol. 41, No. 4, July, 2013, E-mail address: jes@aun.edu.eg 
Mohamed Mahmoud Ismail, M. A. Moustafa Hassan, Incoming and outgoing CT readings based AI techniques for bus bar differential protection faults analysis, pp. 1595 - 1611

\section{1. Training Data For Fault Detection Unit:}

The training data used to train the ANFIS and ANN of the fault detection unit are taken at the no-fault conditions and fault conditions. The fault conditions are carried out at all different fault types (i.e. single phase to ground, phase to phase, double phase to ground and three phase fault ) with inception fault time (Tf) $10 \mathrm{~m}$-sec and fault resistance (Rf) 0.01 , $25,50,75,100$ ohms. There are many types of training data. The input data to the detection unit is the difference between the positive sequence current magnitude measured by incoming CT (Mag1) and the difference between the positive sequence current magnitude measured by outgoing CT (Mag2). The positive sequence current is computed by discrete three phase sequence fundamental module at sampling time $0.0001 \mathrm{sec}$. While the output data one (1) at fault condition and zero (0) at no-fault condition.

a) Testing Data For Fault Detection Unit:

The testing data are chosen at different fault and no fault conditions. The fault conditions are done at different fault resistances and different fault inception times. Some of them are shown in Table.1.

b) Training Data For Fault Location Unit

The training data taken at all types of faults (i.e. single phase to ground, phase to phase, double phase to ground and three phase fault ) with inception fault time (Tf) $10 \mathrm{~m}$-sec and fault resistances (Rf) $0.01,25,50,75,100 \mathrm{ohms}$. There are many types of training data The inputs data are the phase difference of measured positive sequence current by incoming CT (Phas1), the phase difference of measured positive sequence current by outgoing CT (Phas2), and the difference between the measured positive sequence current magnitude of incoming CT and outgoing CT (Mag) .The positive sequence current is computed by discrete three phase sequence fundamental module at sampling time $0.0001 \mathrm{sec}$. While the output data is (1) for internal fault condition and zero (0) for external fault.

c) Testing Data For Fault Location Unit:

The testing data are chosen at different fault conditions which are carried out at different fault resistances and different fault inception times. The testing data are taken randomly with random fault resistances, fault inception times and fault types in each training vector. Due to testing the old method (change at phase angle difference algorithm) is applied. It will be successfully when the input data already defined fault case. But for undefined fault case. The output of the controller apply the change phase angle difference algorithm will be not true, so may be that lead to mal-operation of protection system. ANN and ANFIS is used for the same undefined fault cases. The change at phase angle difference for incoming, and outgoing current transformer are calculated (Phase1 \& Phase 2). The fault detection time for each fault case is detected, The ANN and ANFIS output was (1) at internal fault and (0) for external fault and some of the results are show in table.2.

Journal of Engineering Sciences, Assiut University, Faculty of Engineering, Vol. 41, No. 4, July, 2013,E-mail address: jes@aun.edu.eg 
Mohamed Mahmoud Ismail, M. A. Moustafa Hassan, Incoming and outgoing CT readings based AI techniques for bus bar differential protection faults analysis, pp. 1595- 1611

\section{Table.1.}

Testing Data Of The Fault Detection Unit

\begin{tabular}{|c|c|c|c|c|c|c|c|c|}
\hline $\begin{array}{l}\text { Tf } \\
(\mathrm{Sec})\end{array}$ & $\begin{array}{l}\mathrm{Rf} \\
(\mathrm{Ohm})\end{array}$ & $\begin{array}{l}\text { Fault } \\
\text { type }\end{array}$ & $\begin{array}{l}\text { Fault } \\
\text { Location }\end{array}$ & $\begin{array}{c}\text { Current } \\
\text { change } \\
\text { Mag1 }\end{array}$ & $\begin{array}{c}\text { Current } \\
\text { change } \\
\text { Mag2 }\end{array}$ & $\begin{array}{c}\text { Actual O/P } \\
\text { ANFIS }\end{array}$ & $\begin{array}{c}\text { expected } \\
\text { O/P }\end{array}$ & $\begin{array}{c}\text { Actual O/P } \\
\text { ANN }\end{array}$ \\
\hline 0.014 & 18 & DLG & external & 1.3098 & 1.3098 & 0.9999 & 1 & 0.9999 \\
\hline 0.013 & 20 & $\mathrm{TL}$ & internal & 6.3054 & 0.11 & 1 & 1 & 0.9999 \\
\hline 0.013 & 20 & TL & external & 6.3054 & 6.3054 & 1 & 1 & 1 \\
\hline 0.01 & 60 & DLG & internal & 1.0293 & 0.019 & 0.9999 & 1 & 0.9999 \\
\hline 0.01 & 60 & DLG & external & 1.0293 & 1.0293 & 0.9999 & 1 & 0.9999 \\
\hline 0.003 & 13 & $\mathrm{DL}$ & internal & 17.5054 & 0.3192 & 1 & 1 & 1 \\
\hline 0.003 & 13 & DL & external & 17.5054 & 17.5054 & 1 & 1 & 0.9999 \\
\hline 0.012 & 65 & DLG & internal & 0.7452 & 0.0134 & 0.9999 & 1 & 0.9999 \\
\hline 0.012 & 65 & DLG & external & 0.7452 & 0.7452 & 0.9999 & 1 & 0.9999 \\
\hline 0.005 & 44 & SLG & internal & 2.2758 & 0.0424 & 0.9999 & 1 & 0.9999 \\
\hline 0.005 & 44 & SLG & external & 2.2758 & 2.2758 & 0.9999 & 1 & 0.9999 \\
\hline 0.003 & 61 & $\mathrm{DL}$ & internal & 4.577 & 0.0842 & 1 & 1 & 1 \\
\hline 0.003 & 61 & $\mathrm{DL}$ & external & 4.577 & 4.577 & 1 & 1 & 1 \\
\hline 0.006 & 30 & SLG & internal & 3.2782 & 0.0606 & 1 & 1 & 1 \\
\hline 0.006 & 30 & SLG & external & 3.2782 & 3.2782 & 1 & 1 & 1 \\
\hline 0.011 & 39 & $\mathrm{TL}$ & internal & 4.3303 & 0.0777 & 1 & 1 & 1 \\
\hline 0.011 & 39 & TL & external & 4.3303 & 4.3303 & 1 & 1 & 0.9999 \\
\hline 0.012 & 100 & DLG & internal & 0.4882 & 0.0088 & 0.9999 & 1 & 0.9999 \\
\hline 0.012 & 100 & $\overline{D L G}$ & external & 0.4882 & 0.4882 & 0.9999 & 1 & 0.9999 \\
\hline 0.002 & 37 & $\mathrm{TL}$ & internal & 9.5426 & 0.1821 & 1 & 1 & 1 \\
\hline 0.002 & 37 & TL & external & 9.5426 & 9.5426 & 1 & 1 & 1 \\
\hline 0.003 & 90 & DL & internal & 3.1611 & 0.0583 & 1 & 1 & 1 \\
\hline 0.003 & 90 & DL & external & 3.1611 & 3.1611 & 1 & 1 & 0.9999 \\
\hline 0.016 & 27 & SLG & internal & 1.1932 & 0.0201 & 0.9999 & 1 & 0.9999 \\
\hline 0.016 & 27 & SLG & external & 1.1932 & 1.1932 & 0.9999 & 1 & 0.9999 \\
\hline 0.009 & 60 & $\mathrm{DL}$ & internal & 3.6002 & 0.0653 & 1 & 1 & 1 \\
\hline 0.009 & 60 & DL & external & 3.6002 & 3.6002 & 1 & 1 & 1 \\
\hline 0.001 & 66 & SLG & internal & 1.8797 & 0.0349 & 0.9999 & 1 & 0.9999 \\
\hline 0.001 & 66 & SLG & external & 1.8797 & 1.8797 & 0.9999 & 1 & 0.9999 \\
\hline 0.006 & 58 & $\mathrm{DL}$ & internal & 3.9915 & 0.072 & 1 & 1 & 1 \\
\hline 0.006 & 58 & $\mathrm{DL}$ & external & 3.9915 & 3.9915 & 1 & 1 & 1 \\
\hline 0.004 & 66 & DLG & internal & 1.3811 & 0.0256 & 0.9999 & 1 & 0.9999 \\
\hline 0.004 & 66 & DLG & external & 1.3811 & 1.3811 & 0.9999 & 1 & 0.9999 \\
\hline 0.012 & 82 & DL & internal & 1.4934 & 0.0258 & 0.9999 & 1 & 0.9999 \\
\hline 0.012 & 82 & DL & external & 1.4934 & 1.4934 & 0.9999 & 1 & 0.9999 \\
\hline 0.006 & 100 & SLG & internal & 1.0215 & 0.019 & 0.9999 & 1 & 0.9999 \\
\hline 0.006 & 100 & SLG & external & 1.0215 & 1.0215 & 0.9999 & 1 & 0.9999 \\
\hline 0.015 & 9 & $\mathrm{DL}$ & internal & 4.0606 & 0.057 & 1 & 1 & 1 \\
\hline 0.015 & 9 & $\mathrm{DL}$ & external & 4.0606 & 4.0606 & 1 & 1 & 1 \\
\hline 0.008 & 23 & $\overline{D L G}$ & internal & 2.7176 & 0.0484 & 0.9999 & 1 & 0.9999 \\
\hline 0.008 & 23 & DLG & external & 2.7176 & 2.7176 & 0.9999 & 1 & 0.9999 \\
\hline \multicolumn{4}{|c|}{ No Fault } & 0 & 0 & 0.1065 & 0 & 0.1065 \\
\hline
\end{tabular}

Journal of Engineering Sciences, Assiut University, Faculty of Engineering, Vol. 41, No. 4, July,

2013, E-mail address: jes@aun.edu.eg 
Mohamed Mahmoud Ismail, M. A. Moustafa Hassan, Incoming and outgoing CT readings based AI techniques for bus bar differential protection faults analysis, pp. 1595 - 1611

\section{Table.2.}

Testing Data of the Fault Location Unit

\begin{tabular}{|c|c|c|c|c|c|c|c|c|c|c|}
\hline \multirow[b]{2}{*}{$\mathrm{Tf}$} & \multirow[b]{2}{*}{$\mathrm{Rf}$} & \multirow[b]{2}{*}{$\begin{array}{l}\text { Fault } \\
\text { Type }\end{array}$} & \multirow[b]{2}{*}{$\begin{array}{c}\text { Fault } \\
\text { Location }\end{array}$} & \multicolumn{2}{|c|}{$\begin{array}{c}\text { Phase Angle } \\
\text { Method }\end{array}$} & \multirow[b]{2}{*}{$\begin{array}{l}\text { Detection } \\
\text { Fault } \\
\text { Time } \\
\text { Old } \\
\text { Method }\end{array}$} & \multicolumn{2}{|c|}{$\begin{array}{l}\text { ANFIS } \\
\text { Method }\end{array}$} & \multicolumn{2}{|c|}{ ANN Method } \\
\hline & & & & $\begin{array}{c}\text { Phase } 1 \\
\text { Difference }\end{array}$ & $\begin{array}{c}\text { Phase } 2 \\
\text { Difference }\end{array}$ & & $\begin{array}{c}\text { ANFIS } \\
\mathrm{O} / \mathrm{P}\end{array}$ & $\begin{array}{l}\text { Detecti } \\
\text { on } \\
\text { Fault } \\
\text { Time } \\
\text { ANFIS }\end{array}$ & $\begin{array}{c}\text { ANN } \\
\mathrm{O} / \mathrm{P}\end{array}$ & $\begin{array}{c}\text { Detection } \\
\text { Fault } \\
\text { Time } \\
\text { ANN }\end{array}$ \\
\hline 0.023 & 91 & DL-G & Internal & -0.0106 & 0.0000 & 0.0318 & 1 & 0.0242 & 1 & 0.0244 \\
\hline 0.023 & 91 & DL-G & External & -0.0106 & -0.0106 & 0.0318 & 0 & 0.0318 & 0 & 0.03238 \\
\hline 0.027 & 54 & TL & Internal & -0.0101 & 0.0000 & 0.0322 & 1 & 0.0276 & 1 & 0.0476 \\
\hline 0.027 & 54 & $\mathrm{TL}$ & External & -0.0101 & -0.0101 & 0.0322 & 0 & 0.0322 & 0 & 0.0522 \\
\hline 0.022 & 78 & DL-G & Internal & -0.0118 & 0.0000 & 0.0311 & 1 & 0.0230 & 1 & 0.0230 \\
\hline 0.022 & 78 & $\mathrm{~L}-\mathrm{G}$ & Exter & -0.0118 & -0.0118 & 0.0311 & 0 & 0.0311 & 0 & 0.0311 \\
\hline 0.021 & 74 & SLG & tern & -0.0110 & 0.0000 & 0.0286 & 1 & 0.0223 & 1 & 0.0263 \\
\hline 0.021 & 74 & SLG & xte & -0.0110 & -0.0110 & & 0 & 0.0286 & 0 & 0.0298 \\
\hline 0.026 & 3 & $\mathrm{~L}-\mathrm{G}$ & ter & -0.0276 & 0.0000 & & 1 & 0.0264 & 1 & 0.0274 \\
\hline 0.026 & 3 & DL-G & xte & -0.0276 & -0.0276 & 0.0306 & 0 & 0.0306 & 0 & 0.0354 \\
\hline 0.022 & 22 & TL & Inter & -0.0105 & 0.0000 & 0.0275 & 1 & 0.0224 & 1 & 0.02654 \\
\hline 0.022 & 22 & $\mathrm{~L}$ & $\mathrm{E}$ & -0.0105 & -0.0105 & 0.0275 & 0 & 0.0275 & 0 & 0.02775 \\
\hline 0.026 & 86 & $\mathrm{DL}$ & Intern & -0.0115 & 0.0000 & 0.0276 & 1 & 0.0287 & 1 & 0.0298 \\
\hline 0.026 & 86 & $\mathrm{DL}$ & External & -0.0115 & -0.0115 & 0.0276 & 0 & 0.0276 & 0 & 0.02987 \\
\hline 0.024 & 18 & DL-G & Interr & -0.0101 & 0.0000 & 0.0321 & 1 & 0.0244 & 1 & 0.0244 \\
\hline 0.024 & 18 & $\mathrm{~L}-\mathrm{G}$ & & -0.0101 & -0.0101 & 0.0321 & 0 & 0.0321 & 0 & 0.0321 \\
\hline 0.023 & 20 & TL & & -0.0104 & 0.0000 & 0.0288 & 1 & 0.0234 & 1 & 0.03234 \\
\hline 0.023 & 20 & & & -0.0104 & -0.0104 & & 0 & 0.0288 & 0 & 0.02298 \\
\hline 0.02 & 60 & DL-G & ter & -0.0538 & 0.0000 & 0.0230 & 1 & 0.0214 & 1 & 0.0254 \\
\hline 0.02 & 60 & DL-G & Fyternal & -0.0538 & -0.0538 & 0.0230 & 0 & 0.0230 & 0 & 0.02760 \\
\hline 0.023 & 13 & DL & Internal & -0.0168 & 0.0000 & 0.0301 & 1 & 0.0233 & 1 & 0.02673 \\
\hline 0.023 & 13 & DL & External & -0.0168 & -0.0168 & 0.0301 & 0 & 0.0301 & 0 & 0.05401 \\
\hline 0.022 & 65 & DL-G & Internal & -0.0107 & 0.0000 & 0.0311 & 1 & 0.0229 & 1 & 0.07829 \\
\hline 0.022 & 65 & DL-G & External & -0.0107 & -0.0107 & 0.0311 & 0 & 0.0311 & 0 & 0.05611 \\
\hline 0.025 & 44 & SLG & Internal & -0.0117 & 0.0000 & 0.0260 & 1 & 0.0274 & 1 & 0.02774 \\
\hline 0.025 & 44 & SLG & External & -0.0117 & -0.0117 & 0.0260 & 0 & 0.0260 & 0 & 0.0260 \\
\hline 0.023 & 61 & DL & Internal & -0.0134 & 0.0000 & 0.0298 & 1 & 0.0235 & 1 & 0.02687 \\
\hline 0.023 & 61 & DL & External & -0.0134 & -0.0134 & 0.0298 & 0 & 0.0298 & 0 & 0.02987 \\
\hline 0.026 & 30 & SLG & Internal & -0.0100 & 0.0000 & 0.0264 & 1 & 0.0272 & 1 & 0.02776 \\
\hline 0.026 & 30 & SLG & External & -0.0100 & -0.0100 & 0.0264 & 0 & 0.0264 & 0 & 0.02664 \\
\hline 0.021 & 39 & TL & Internal & -0.0102 & 0.0000 & 0.0261 & 1 & 0.0215 & 1 & 0.0215 \\
\hline
\end{tabular}

Journal of Engineering Sciences, Assiut University, Faculty of Engineering, Vol. 41, No. 4, July,

2013, E-mail address: jes@aun.edu.eg 
Mohamed Mahmoud Ismail, M. A. Moustafa Hassan, Incoming and outgoing CT readings based AI techniques for bus bar differential protection faults analysis, pp. 1595-1611

The changing of the system parameters like source voltage and load very effective on the protection system and should be studied. The same differential protection system without any additional training process for the ANFIS and ANN controller is used. The system will be tested when increasing the source voltage by $2.5 \%$ and then decreasing the source voltage by $2.5 \%$. Under different faults types, faults resistances, fault inception time and different fault location. The results are recorded as illustrated in Table (3) and Table (4) respectively. Also the system will be tested when increasing the load by $15 \%$ and then decreasing the load by $15 \%$. The testing will be on different faults types, faults resistances, fault inception time and different fault location. The results are recorded and presented in Table (5) and Table (6) respectively.

\section{Table 3.}

Testing Fault Location Unit At $+2.5 \%$ Of Source Voltage

\begin{tabular}{|c|c|c|c|c|c|c|c|c|c|c|}
\hline & & & & \multicolumn{2}{|l|}{ Phase Angle Method } & & \multicolumn{2}{|l}{ ANFIS Method } & \multicolumn{2}{|c|}{ ANN Method } \\
\hline Tf & Rf & $\begin{array}{c}\text { Fault } \\
\text { Type }\end{array}$ & $\begin{array}{c}\text { Fault } \\
\text { Location }\end{array}$ & $\begin{array}{c}\text { Phase 1 } \\
\text { Difference }\end{array}$ & $\begin{array}{c}\text { Phase 2 } \\
\text { Difference }\end{array}$ & $\begin{array}{c}\text { Detection } \\
\text { Fault } \\
\text { Time } \\
\text { Old Method }\end{array}$ & $\begin{array}{c}\text { ANFIS } \\
\text { O/P }\end{array}$ & $\begin{array}{c}\text { Detection } \\
\text { Fault } \\
\text { Time } \\
\text { ANFIS }\end{array}$ & $\begin{array}{c}\text { ANN } \\
\text { O/P }\end{array}$ & $\begin{array}{c}\text { Detection } \\
\text { Fault } \\
\text { Time } \\
\text { ANN }\end{array}$ \\
\hline 0.023 & 91 & DL-G & Internal & -0.0109 & 0.0002 & 0.0247 & 1 & 0.0241 & 1 & 0.025 \\
\hline 0.023 & 91 & DL-G & External & -0.0108 & -0.0108 & 0.0247 & 0 & 0.0247 & 0 & 0.034 \\
\hline 0.027 & 54 & TL & Internal & -0.001 & 0 & 0.0276 & 1 & 0.0276 & 1 & 0.039 \\
\hline 0.027 & 54 & TL & External & -0.0009 & -0.000903 & 0.0276 & 0 & 0.0276 & 0 & 0.032 \\
\hline 0.021 & 74 & SLG & Internal & -0.0233 & 0.0003539 & 0.0223 & 1 & 0.0223 & 1 & 0.0230 \\
\hline 0.021 & 74 & SLG & External & -0.0233 & -0.023275 & 0.0223 & 0 & 0.0223 & 0 & 0.033 \\
\hline 0.026 & 86 & DL & Internal & 0.0604 & -0.0008 & 0.0287 & 1 & 0.0287 & 1 & 0.027 \\
\hline 0.026 & 86 & DL & External & 0.06045 & 0.0604 & 0.0287 & 0 & 0.0287 & 0 & 0.0287 \\
\hline 0.024 & 18 & DL-G & Internal & -0.0129 & 0 & 0.0244 & 1 & 0.0244 & 1 & 0.0264 \\
\hline 0.024 & 18 & DL-G & External & -0.0129 & -0.0129 & 0.0244 & 0 & 0.0244 & 0 & 0.0344 \\
\hline 0.023 & 20 & TL & Internal & -0.0014 & 0 & 0.0234 & 1 & 0.0234 & 1 & 0.0264 \\
\hline 0.023 & 20 & TL & External & -0.0014 & -0.0014 & 0.0234 & 0 & 0.0234 & 0 & 0.02775 \\
\hline 0.023 & 13 & DL & Internal & -0.0334 & 0.0002 & 0.0233 & 1 & 0.0233 & 1 & 0.0278 \\
\hline 0.023 & 13 & DL & External & -0.0334 & -0.0334 & 0.0233 & 0 & 0.0233 & 0 & 0.02787 \\
\hline 0.026 & 30 & SLG & Internal & 0.04815 & -0.0006 & 0.0272 & 1 & 0.0272 & 1 & 0.0244 \\
\hline 0.026 & 30 & SLG & External & 0.04815 & 0.04815 & 0.0272 & 0 & 0.0272 & 0 & 0.0331 \\
\hline
\end{tabular}

Journal of Engineering Sciences, Assiut University, Faculty of Engineering, Vol. 41, No. 4, July, 2013, E-mail address: jes@aun.edu.eg 
Mohamed Mahmoud Ismail, M. A. Moustafa Hassan, Incoming and outgoing CT readings based AI techniques for bus bar differential protection faults analysis, pp. 1595 - 1611

\section{Table 4.}

Testing Fault Location Unit At -2.5\% Of Source Voltage

\begin{tabular}{|c|c|c|c|c|c|c|c|c|c|c|}
\hline & & & & Phase Ar & gle Method & & ANFIS & Method & ANN & Method \\
\hline $\mathrm{Tf}$ & $\mathrm{Rf}$ & $\begin{array}{l}\text { Fault } \\
\text { Type }\end{array}$ & $\begin{array}{c}\text { Fault } \\
\text { Location }\end{array}$ & $\begin{array}{c}\text { Phase } 1 \\
\text { Difference }\end{array}$ & $\begin{array}{c}\text { Phase } 2 \\
\text { Difference }\end{array}$ & $\begin{array}{c}\text { Detection } \\
\text { Fault } \\
\text { Time } \\
\text { Old } \\
\text { Method }\end{array}$ & $\begin{array}{c}\text { ANFIS } \\
\mathrm{O} / \mathrm{P}\end{array}$ & $\begin{array}{c}\text { Detection } \\
\text { Fault } \\
\text { Time } \\
\text { ANFIS }\end{array}$ & $\begin{array}{l}\text { ANN } \\
\mathrm{O} / \mathrm{P}\end{array}$ & $\begin{array}{l}\text { Detecti } \\
\text { on } \\
\text { Fault } \\
\text { Time } \\
\text { ANN }\end{array}$ \\
\hline 0.023 & 91 & DL-G & Internal & -0.0108 & 0.00022 & 0.0247 & 1 & 0.0242 & 1 & 0.025 \\
\hline 0.023 & 91 & DL-G & External & -0.0106 & -0.0107 & 0.0247 & 0 & 0.0247 & 0 & 0.026 \\
\hline 0.027 & 54 & TL & Internal & -0.0009 & 0 & 0.0276 & 1 & 0.0276 & 1 & 0.027 \\
\hline 0.027 & 54 & $\mathrm{TL}$ & External & -0.0009 & -0.0009 & 0.0276 & 0 & 0.0276 & 0 & 0.028 \\
\hline 0.021 & 74 & SLG & Internal & -0.0232 & 0.0003 & 0.0223 & 1 & 0.0223 & 1 & 0.0230 \\
\hline 0.021 & 74 & SLG & External & -0.0233 & -0.0233 & 0.0223 & 0 & 0.0223 & 0 & 0.024 \\
\hline 0.026 & 86 & DL & Internal & -0.0207 & 0.0002 & 0.0266 & 1 & 0.0266 & 1 & 0.0272 \\
\hline 0.026 & 86 & DL & External & -0.0207 & -0.0208 & 0.0266 & 0 & 0.0266 & 0 & 0.028 \\
\hline 0.024 & 18 & DL-G & Internal & -0.0129 & 0 & 0.0244 & 1 & 0.0244 & 1 & 0.0234 \\
\hline 0.024 & 18 & DL-G & External & -0.0129 & -0.0129 & 0.0244 & 0 & 0.0244 & 0 & 0.0264 \\
\hline 0.023 & 20 & TL & Internal & -0.0014 & $1.509 \mathrm{E}-05$ & 0.0234 & 1 & 0.0234 & 1 & 0.0245 \\
\hline 0.023 & 20 & TL & External & -0.0014 & -0.0014 & 0.0234 & 0 & 0.0234 & 0 & 0.0265 \\
\hline 0.023 & 13 & DL & Internal & -0.0178 & 0.0025 & 0.0269 & 1 & 0.0233 & 1 & 0.033 \\
\hline 0.023 & 13 & DL & External & -0.0178 & -0.0178 & 0.0269 & 0 & 0.0269 & 0 & 0.0276 \\
\hline 0.026 & 30 & SLG & Internal & 0.0530 & -0.0007 & 0.0273 & 1 & 0.0273 & 1 & 0.0274 \\
\hline
\end{tabular}

Journal of Engineering Sciences, Assiut University, Faculty of Engineering, Vol. 41, No. 4, July, 2013,E-mail address: jes@aun.edu.eg 
Mohamed Mahmoud Ismail, M. A. Moustafa Hassan, Incoming and outgoing CT readings based AI techniques for bus bar differential protection faults analysis, pp. 1595-1611

\section{Table 5.}

Testing Fault Location Unit at $+15 \%$ Of Load

\begin{tabular}{|c|c|c|c|c|c|c|c|c|c|c|}
\hline \multirow[b]{2}{*}{ Tf } & \multirow[b]{2}{*}{$\mathrm{Rf}$} & \multirow[b]{2}{*}{$\begin{array}{l}\text { Fault } \\
\text { Type }\end{array}$} & \multirow[b]{2}{*}{$\begin{array}{c}\text { Fault } \\
\text { Location }\end{array}$} & \multicolumn{2}{|c|}{ Phase Angle Method } & \multirow[b]{2}{*}{$\begin{array}{l}\text { Detection } \\
\text { Fault } \\
\text { Time } \\
\text { Old } \\
\text { Method }\end{array}$} & \multicolumn{2}{|c|}{ ANFIS Method } & \multirow{2}{*}{$\begin{array}{l}\text { ANN } \\
\\
\text { ANN } \\
\text { O/P }\end{array}$} & \multirow{2}{*}{$\begin{array}{c}\text { Method } \\
\text { Detection } \\
\text { Fault } \\
\text { Time } \\
\text { ANN }\end{array}$} \\
\hline & & & & $\begin{array}{c}\text { Phase } 1 \\
\text { Difference }\end{array}$ & $\begin{array}{c}\text { Phase } 2 \\
\text { Difference }\end{array}$ & & $\begin{array}{c}\text { ANFIS } \\
\mathrm{O} / \mathrm{P}\end{array}$ & $\begin{array}{c}\text { Detection } \\
\text { Fault } \\
\text { Time } \\
\text { ANFIS }\end{array}$ & & \\
\hline 0.023 & 91 & DL-G & Internal & -0.0104 & 0.00023 & 0.0248 & 1 & 0.0242 & 1 & 0.033 \\
\hline 0.023 & 91 & DL-G & External & -0.0104 & -0.0104 & 0.0248 & 0 & 0.0248 & 0 & 0.026 \\
\hline 0.027 & 54 & TL & Internal & -0.00081 & 0 & 0.0276 & 1 & 0.0276 & 1 & 0.028 \\
\hline 0.027 & 54 & $\mathrm{TL}$ & External & -0.0008 & -0.0008 & 0.0276 & 0 & 0.0276 & 0 & 0.0278 \\
\hline 0.021 & 74 & SLG & Internal & -0.0199 & 0 & 0.0223 & 1 & 0.0223 & 1 & 0.0230 \\
\hline 0.021 & 74 & SLG & External & -0.0107 & -0.0107 & 0.0218 & 0 & 0.0218 & 0 & 0.024 \\
\hline 0.026 & 86 & DL & Internal & 0.05154 & -0.0008 & 0.0287 & 1 & 0.0287 & 1 & 0.029 \\
\hline 0.026 & 86 & DL & External & 0.01273 & 0.01273 & 0.0277 & 0 & 0.0277 & 0 & 0.028 \\
\hline 0.024 & 18 & DL-G & Internal & -0.011 & $9.985 \mathrm{E}-05$ & 0.0244 & 1 & 0.0244 & 1 & 0.0254 \\
\hline 0.024 & 18 & DL-G & External & -0.0111 & -0.011 & 0.0244 & 0 & 0.0244 & 0 & 0.0264 \\
\hline 0.023 & 20 & TL & Internal & -0.0012 & 0 & 0.0234 & 1 & 0.0234 & 1 & 0.0236 \\
\hline 0.023 & 20 & $\mathrm{TL}$ & External & -0.0012 & -0.0012 & 0.0234 & 0 & 0.0234 & 0 & $\begin{array}{r}0.0277 \\
5\end{array}$ \\
\hline 0.023 & 13 & DL & Internal & -0.0286 & 0.00022 & 0.0233 & 1 & 0.0233 & 1 & 0.0298 \\
\hline 0.023 & 13 & DL & External & -0.0287 & -0.0286 & 0.0233 & 0 & 0.0233 & 0 & $\begin{array}{r}0.0298 \\
7\end{array}$ \\
\hline 0.026 & 30 & SLG & Internal & 0.04527 & -0.0007 & 0.0273 & 1 & 0.0273 & 1 & 0.028 \\
\hline
\end{tabular}

Journal of Engineering Sciences, Assiut University, Faculty of Engineering, Vol. 41, No. 4, July, 2013, E-mail address: jes@aun.edu.eg 
Mohamed Mahmoud Ismail, M. A. Moustafa Hassan, Incoming and outgoing CT readings based AI techniques for bus bar differential protection faults analysis, pp. 1595 - 1611

\section{Table 6.}

Testing Fault Location Unit at $-15 \%$ Of Load:

\begin{tabular}{|c|c|c|c|c|c|c|c|c|c|c|}
\hline & & & & Phase An & e Method & & ANFI & Method & ANN & Method \\
\hline $\mathrm{Tf}$ & $\mathrm{Rf}$ & $\begin{array}{l}\text { Fault } \\
\text { Type }\end{array}$ & $\begin{array}{c}\text { Fault } \\
\text { Location }\end{array}$ & $\begin{array}{l}\text { Phase } 1 \\
\text { Difference }\end{array}$ & $\begin{array}{c}\text { Phase } 2 \\
\text { Difference }\end{array}$ & $\begin{array}{l}\text { Detection } \\
\text { Fault } \\
\text { Time } \\
\text { Old Method }\end{array}$ & $\begin{array}{c}\text { ANFIS } \\
\text { O/P }\end{array}$ & $\begin{array}{c}\text { Detection } \\
\text { Fault } \\
\text { Time } \\
\text { ANFIS }\end{array}$ & $\begin{array}{c}\mathrm{ANN} \\
\mathrm{O} / \mathrm{P}\end{array}$ & $\begin{array}{c}\text { Detection } \\
\text { Fault } \\
\text { Time } \\
\text { ANN }\end{array}$ \\
\hline 0.023 & 91 & DL-G & External & -0.0108 & -0.0108 & 0.0246 & 0 & 0.0246 & 1 & 0.025 \\
\hline 0.027 & 54 & TL & Internal & -0.0011 & 0 & 0.0276 & 1 & 0.0276 & 0 & 0.028 \\
\hline 0.027 & 54 & TL & External & -0.0011 & -0.0012 & 0.0276 & 0 & 0.0276 & 1 & 0.0276 \\
\hline 0.021 & 74 & SLG & Internal & -0.0264 & 0.00036 & 0.0223 & 1 & 0.0223 & 0 & 0.0245 \\
\hline 0.021 & 74 & SLG & External & -0.0267 & -0.0267 & 0.0223 & 0 & 0.0223 & 1 & 0.024 \\
\hline 0.026 & 86 & DL & Internal & 0.0692 & -0.0008 & 0.0287 & 1 & 0.0287 & 0 & 0.023 \\
\hline 0.026 & 86 & DL & External & 0.06928 & 0.0693 & 0.0287 & 0 & 0.0287 & 1 & 0.027 \\
\hline 0.024 & 18 & DL-G & Internal & -0.0148 & 0 & 0.0244 & 1 & 0.0244 & 1 & 0.0266 \\
\hline 0.024 & 18 & DL-G & External & -0.0147 & -0.0147 & 0.0244 & 0 & 0.0244 & 0 & 0.0267 \\
\hline 0.023 & 20 & TL & Internal & -0.0016 & 0 & 0.0234 & 1 & 0.0234 & 1 & 0.024 \\
\hline 0.023 & 20 & $\mathrm{TL}$ & External & -0.0016 & -0.0016 & 0.0234 & 0 & 0.0234 & 0 & 0.0276 \\
\hline 0.023 & 13 & DL & Internal & -0.0381 & 0.00022 & 0.0233 & 1 & 0.0233 & 1 & 0.03 \\
\hline 0.023 & 13 & DL & External & -0.0381 & -0.0381 & 0.0233 & 0 & 0.0233 & 0 & 0.029 \\
\hline 0.026 & 30 & SLG & Internal & 0.05517 & -0.0007 & 0.0272 & 1 & 0.0272 & 1 & 0.0244 \\
\hline
\end{tabular}

Tables (3), (4), (5) and (6) show the output of ANFIS and ANN controllers when the power system parameters changed. The ANFIS and ANN outputs for all testing fault cases were 1 for internal fault and 0 for external fault. This results prove that the protection system using the phase angle difference change by ANFIS and ANN techniques is very successfully although the power system parameters changing. Also this is an indication of the stability of the proposed protection system due to the power system parameters variation, while the fault detection time is slightly changed from ANFIS and ANN method and it is still in the both methods in the accepted margin for the power system trip action.

Journal of Engineering Sciences, Assiut University, Faculty of Engineering, Vol. 41, No. 4, July, 2013,E-mail address: jes@aun.edu.eg 
Mohamed Mahmoud Ismail, M. A. Moustafa Hassan, Incoming and outgoing CT readings based AI techniques for bus bar differential protection faults analysis, pp. 1595-1611

\section{Conclusions}

In this paper, An Artificial Intelligent approach of bus bar differential protection for fault detection and location in distribution system protection was introduced. The fault location in this article is used to determine if the fault occurs on the bus bar which is internal fault, while the fault outside the bus bar system is an indication of external fault. The proposed approach performs successfully for the two main protection tasks. For the fault detection task, all the testing data for the ANN and ANFIS detectors give the correct output within the given periods that are mentioned before. For the fault location task, all the testing data for the ANFIS and ANN locator units give the correct estimated output with minimum error. Moreover, the testing procedure takes into account the randomness of the faults on distribution feeder with respect to the time of occurrence, fault location, fault type and resistance. The Phasor concept is used in this paper to overcome the problem of current transformer saturation and mismatch.

\section{References}

[1] L.G.Hewitson, Markbrown, Ramesh and Balakrishman, “ Practical power system protection “, Book, ISBN: $0750663979,2004$.

[2] M. R. Aghaebrahimi, H. Khorashadi Zadeh, "Fuzzy Neuro Approach to Bus bar Protection; Design and Implementation “, International Journal of Information and Communication Engineering , 2006, pp 350-354

[3] Dmitrienko, A. M.; Sinichkin, A. Yu. Russian, "Fast differential bus bar protection based on REB670 " , Russian Electrical Engineering, vol. 82 issue 1 January 2011. p. 23 - 28

[4] Y.C.kang, J.S.Yun, B.E.Lee , S.H.Lee , S.H.Kang, S.I.Jang and Y.G.Kim , “ Bus bar differential protection in conjunction with a current transformer compensating algorithm ", IET Generation , Transmission . Distribution .Vol.2, No, 1, Jan -2008, pp 100 - 109.

[5] Bodankasztenny, Gustawo Brunello and Lumomin Sevov, " Digital low impedance bus differential protection with reduced requirements for C.T ", Transmission and Distribution Conference and Exposition 2001, IEEE/PES Volume 2, Issue, 2001, pp: 703-708.

[6] P.Jena and A.Kpradham , “ Bus bar protection a solution to C.T saturation " , Fifteenth National Power System Conference (NPSC) , Bombay, Dec-2008

[7] N.W. Kinhekar, Sangeet. A Daingade , and Ajayshree Kinhekar , "Current differential Protection of alternator stator winding ", International Conference On Power System Transients (IPST2009), Kyoto Japan , June 2009

[8] J.G Andrichak and Jorge Cardenas, “ Bus differential protection ”, Western Protective Relay Conference Spoken, Washington, October 24,1995

[9] Arun .G. Phadke \& James. S. Throp, "Computer relaying for power systems ", book , ohn Wiley \& Sons, 2009, ISBN 0470747579, 9780470747575, 344 pages

[10] Pullman .WA USA, "Suitability using EMTP models", Schweitzer Engineering Laboratories, INC., 1999.

[11] S.R.Samantaray, L.N.Tripathy, P.K.Dash, G.Panda , “ S-transform based directional bus bar protection “, TENCON IEEE conference, India , 2008 , pp 1-6

Journal of Engineering Sciences, Assiut University, Faculty of Engineering, Vol. 41, No. 4, July, 2013,E-mail address: jes@aun.edu.eg 
Mohamed Mahmoud Ismail, M. A. Moustafa Hassan, Incoming and outgoing CT readings based AI techniques for bus bar differential protection faults analysis, pp. 1595 - 1611

[12] Mohamed Salah El-din Ahmed, "An artificial intelligence approach for high impedance faults detection, classification and location in distribution systems using adaptive neuro fuzzy inference systems ". Master Thesis, Cairo University, Faculty Of Engineering, 2011.

[13] Shiyong Wang, Xinzhou Dong, and Shenxing Shi, "A novel bus bar protection scheme based wavelet multi - resolution signal decomposition ". Dept of Electrical Engineering Tsinghua University, China, 2010, pp 1-5

[14] M.E.Mohammed, “ High speed differential bus bar protection using wavelet -packet transform “ , Electrical Engineering Department, Mater degree , Faculty Of Engineering, Helwan University, Cairo, Egypt, 2011.

[15] K.alus.Peter Brand, senior member, IEEE, and Wolfgang Wimmer, "Use Of Distribution topology detection for applications in substation automation ", IEEE Bucharest power Tech conference, Jun 28th - Jul 2 nd -2009, Romania , pp 1-6

[16] Zahra Moravej, Moshanir Co. “ Minimal Radial Basis function network based bus protection system using OCT ", 5th WSEAS/IASME Int. Conf. on systems theory and scientific computation, Malta, September 15-17, 2005 , pp 206-212

[17] M.M.Eissa ," A novel wavelet approach to bus bar protection during CT saturation and ratio mismatch ", Master degree , Department Of Electrical Engineering , Faculty Of Engineering , Helwan university , Helwan, Cairo ,Egypt , 30-Jul-2003 .

[18] Tamer Sayed Saleh, "A novel approach to distance protection of transmission lines using adaptive neuro fuzzy inference system ", Master degree, Cairo University, Faculty of Engineering, 2011

[19] S.N.Sivanandam, S.S Sumathi and S.N Deepa, “ Introduction to fuzzy logic using mat-lab ", Springer Science, 2007.

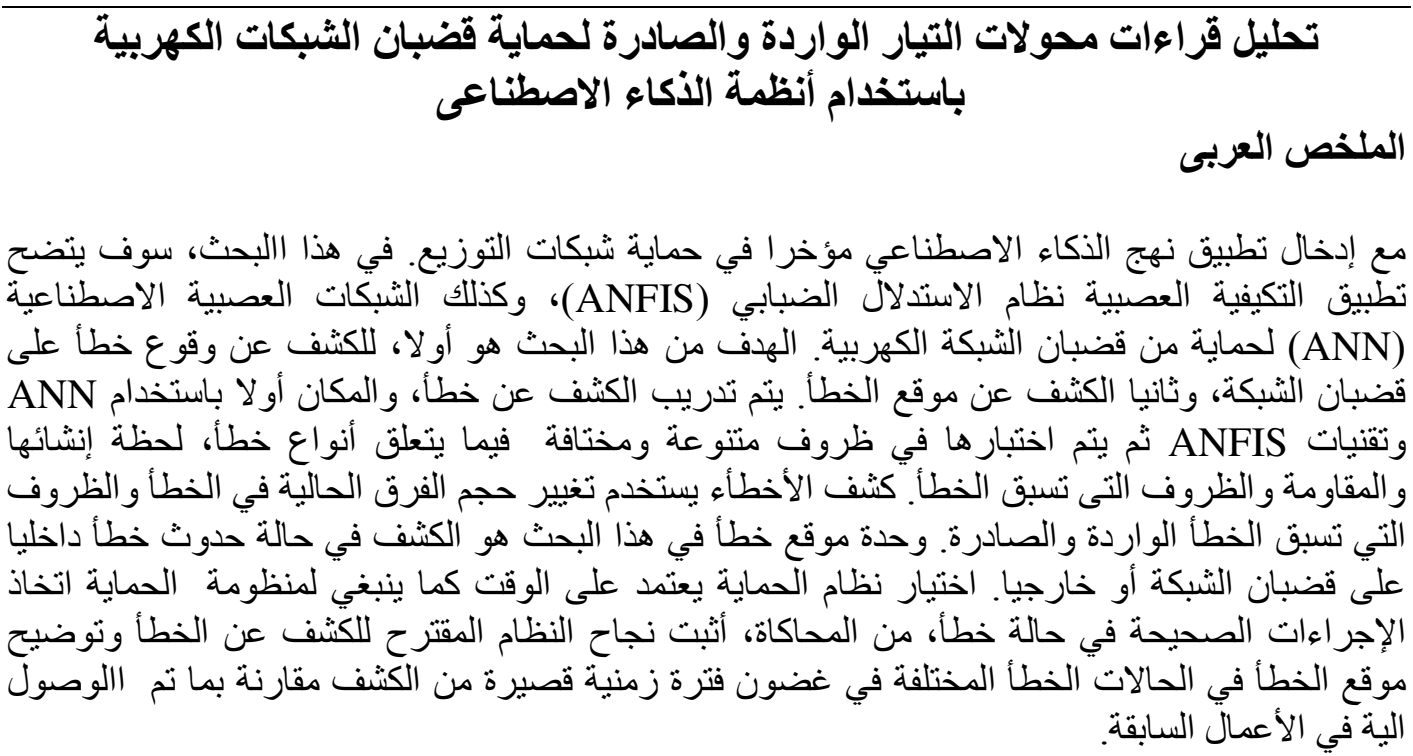

Journal of Engineering Sciences, Assiut University, Faculty of Engineering, Vol. 41, No. 4, July, 2013,E-mail address: jes@aun.edu.eg 